\title{
A Validation Study of the Web Screening Questionnaire (WSQ) Compared With the Mini-International Neuropsychiatric Interview-Plus (MINI-Plus)
}

Denise Meuldijk ${ }^{1}$, PhD; Erik J Giltay ${ }^{2}, \mathrm{PhD}, \mathrm{MD}$; Ingrid VE Carlier ${ }^{2}, \mathrm{PhD}$; Irene M van Vliet ${ }^{2}, \mathrm{MD}, \mathrm{PhD}$; Albert M van Hemert ${ }^{2}$, Prof. Dr. MD, PhD.; Frans G Zitman², Prof. Dr. MD, PhD.

\footnotetext{
${ }^{1}$ School of Psychology, Illawarra Health and Medical Research Institute, University of Wollongong, Wollongong, New South Wales, Australia

${ }^{2}$ Department of Psychiatry, Leiden University Medical Centre, Leiden, Netherlands
}

\section{Corresponding Author:}

Denise Meuldijk, $\mathrm{PhD}$

School of Psychology

Illawarra Health and Medical Research Institute

University of Wollongong

Northfields Avenue

Wollongong, New South Wales,

Australia

Phone: 61242214086

Fax: 61242214086

Email: meuldijk@uow.edu.au

\section{Abstract}

Background: There is a need for brief screening methods for psychiatric disorders in clinical practice. This study assesses the validity and accuracy of a brief self-report screening questionnaire, the Web Screening Questionnaire (WSQ), in detecting psychiatric disorders in a study group comprising the general population and psychiatric outpatients aged 18 years and older.

Objective: The aim of this study was to investigate whether the WSQ is an adequate test to screen for the presence of depressive and anxiety disorders in clinical practice.

Methods: Participants were 1292 adults (1117 subjects from the general population and 175 psychiatric outpatients), aged 18 to 65 years. The discriminant characteristics of the WSQ were examined in relation to the ("gold standard") Mini-International Neuropsychiatric Interview-Plus (MINI-Plus) disorders, by means of sensitivity, specificity, area under the curve (AUC), and positive and negative predictive values (PPVs, NPVs).

Results: The specificity of the WSQ to individually detect depressive disorders, anxiety disorders, and alcohol abuse or dependence ranged from 0.89 to 0.97 for most disorders, with the exception of post-traumatic stress disorder (0.52) and specific phobia (0.73). The sensitivity values ranged from 0.67 to 1.00 , with the exception of depressive disorder (0.56) and alcohol abuse or dependence (0.56). Given the low prevalence of separate disorders in the general population sample, NPVs were extremely high across disorders $(\geq 0.97)$, whereas PPVs were of poor strength (range 0.02-0.33).

Conclusions: In this study group, the WSQ was a relatively good screening tool to identify individuals without a depressive or anxiety disorder, as it accurately identified those unlikely to suffer from these disorders (except for post-traumatic stress disorders and specific phobias). However, in case of a positive WSQ screening result, further diagnostic procedures are required.

(JMIR Ment Health 2017;4(3):e35) doi: 10.2196/mental.5453

\section{KEYWORDS}

depressive disorders; anxiety disorders; surveys and questionnaires; diagnostic, brief; clinical practice

\section{Introduction}

Structured diagnostic interviews such as the Composite International Diagnostic Interview (CIDI) [1] and the Structured
Clinical Interview for DSM-III-R (SCID) [2] are considered gold standards in research, used to diagnose psychiatric disorders in a standardized way $[1,3,4]$. However, they are less suitable for clinical practice because their administration is time 
consuming, and they can only be administered by well-trained interviewers [5]. The Mini-International Neuropsychiatric Interview-Plus (MINI-Plus) [6] is a much shorter diagnostic interview with diagnostic properties similar to the CIDI $[6,7]$. However, the MINI-Plus also requires trained interviewers and takes up to 30 min to complete, making it costly for routine use in clinical practice. Therefore, because these interviews are often impractical to be used as a screener for routine use, a reliable, valid, and briefly self-rating screening questionnaire is desired. The Web Screening Questionnaire (WSQ) [8] was developed to quickly screen for common psychiatric disorders (ie, anxiety or depressive disorders and alcohol abuse or dependence). This Internet-based, self-report screening questionnaire consists of only 15 items and requires less than 5 min to complete. The WSQ has good to excellent validity for social phobia, panic disorder with agoraphobia, agoraphobia (without panic disorder), obsessive compulsive disorder (OCD), and alcohol abuse or dependence (sensitivity ranges from 0.72-1.00; and specificity from 0.63-0.80) [8]. Slightly more modest psychometric properties were reported for depressive disorder, generalized anxiety disorder (GAD), post-traumatic stress disorder (PTSD), specific phobia, and panic disorder (without agoraphobia), that is, sensitivity 0.80 to 0.93 ; specificity 0.44 to 0.51 [8]. These data reflect the validation of the WSQ compared with CIDI diagnoses ascertained in the general population with 6-month prevalence rates of the Diagnostic and Statistical Manual, 4th edition-Text Revision (DSM-IV-TR) diagnoses [9]. As the WSQ screens for current symptoms [8], it is relevant to test the WSQ against current DSM-IV diagnoses.

This study examines the validity and accuracy of the WSQ as a screener against 1-month prevalence MINI-Plus disorders covered by the WSQ. The study group mainly comprised a general population sample recruited from primary care registrations. To increase the prevalence of psychiatric disorders, we enriched this general population sample with a smaller sample of psychiatric outpatients to form one large study group.

\section{Methods}

\section{Sample}

For this study, to ensure statistical power of the analyses, participants from a general population study and participants from a pragmatic randomized controlled trial (RCT) conducted in clinical practice were combined into one large study group.

The 1302 participants from the general population were recruited (from November 2009 to January 2011) from the administration of eight university-affiliated general practices in the vicinity of Leiden, the Netherlands. In the Netherlands, since nearly $100 \%$ of the population is registered with a general practitioner (GP), the primary care sample is equivalent to a general population sample [10,11]. To form a nonpatient control group, representative of a population referred for suspected (but not necessarily diagnosed with) mood, anxiety and/or somatoform disorders, four exclusion criteria were applied by Schulte-van Maaren and colleagues (2013) [12]: (1) treatment in a secondary psychiatric care center in the last 6 months for psychiatric problems and/or dependence on alcohol or drugs; (2) hearing impairment or limited cognitive abilities such as aphasia, severe dyslexia, or dementia; (3) illiteracy or insufficient mastery of the Dutch language; and (4) suffering from a potentially lethal disorder. The initial study was designed to generate reference values in primary care for questionnaires used in the assessment of psychopathology. Details of this study by Schulte-van Maaren and colleagues (2013) are described elsewhere [12]. This study focuses on the main aspects relevant for the current research question.

The general population sample derived from the study of Schulte-van Maaren et al (2013) [12] was enriched with a sample of 182 secondary care outpatients who were originally recruited for a pragmatic RCT and in whom the WSQ and the MINI-Plus were assessed at baseline. This RCT is published in Meuldijk and colleagues (2012) [13]. The trial was conducted (from March 2010 to December 2012) at five outpatient mental health clinics in and around Leiden of Rivierduinen (RD), a secondary Regional Mental Health Provider (RHMP) in the province of South-Holland, the Netherlands. Eligible participants were patients aged 18-65 years, referred to the mental health clinics by their GP for the treatment of a current mild to moderate anxiety and/or depressive disorder including depressive disorder, dysthymia, panic disorder (with or without agoraphobia), social phobia, specific phobia, GAD, OCD, and PTSD. Exclusion criteria were (1) suicidal or homicidal risk; (2) delusions, hallucinations, bipolar, or psychotic disorder; (3) severe social dysfunction; and/or (4) insufficient knowledge of the Dutch language.

In both subsamples, the assessment included (among others) the MINI-Plus and the WSQ. Of the initial general population sample of 1302 participants, 185 had incomplete WSQ data, leaving 1117 participants for inclusion in the present analysis. Of the outpatient sample of 182 patients, 6 had incomplete WSQ data and 1 MINI-Plus interview was incomplete, resulting in 175 outpatients. Thus, the (combined) study group for this study consisted of $(1117+175) 1292$ participants.

The study protocol for both samples was approved by the medical ethical committee of the Leiden University Medical Center.

\section{Web Screening Questionnaire (WSQ)}

The WSQ (see Multimedia Appendix 1) is a 15-item, self-report instrument that screens for depressive disorder, GAD, panic disorder with or without agoraphobia, social phobia, specific phobia, OCD, PTSD, agoraphobia, suicidality, and alcohol abuse or dependence [8]. The RCT of Meuldijk and colleagues excluded participants with a moderate to high suicidality risk and/or suicidal ideation [13]. Therefore, in this study, the WSQ item that assesses the risk of suicide or self-harm was not included in the analysis. The WSQ is based on the screening questionnaire of Marks and colleagues [14]. Compared with the 6-months CIDI diagnoses, in the general population, the WSQ has moderate to good screening properties (sensitivity 0.72 to 1.00 ; specificity 0.44 to 0.80 ) [8]. Depression, panic disorder with agoraphobia, and alcohol dependence were each assessed by two items, whereas the other disorders were assessed by single items. The same WSQ cut-off scores were applied as used in the study by Donker and colleagues (2006) [8]. 


\section{Mini-International Neuropsychiatric Interview-Plus (MINI-Plus)}

The MINI-Plus 5.0.0, Dutch version, was used as the "gold standard" reference [6]. The MINI-Plus is a structured and standardized diagnostic interview used to determine the most common psychiatric disorders according to axis I DSM-IV-TR [9] and the International Classification of Diseases and Related Health Problems (ICD-10) [6].

For this study, we used the diagnoses of (1) mood disorders (depression and dysthymia), (2) anxiety disorders (panic disorder with or without agoraphobia, agoraphobia, social phobia, specific phobia, GAD, PTSD [type I or single trauma], and OCD), and (3) alcohol abuse or dependence. The MINI-Plus has good psychometric properties and is widely used to support diagnostics in psychiatry. The MINI-Plus was conducted by trained research nurses. As the WSQ screens for current diagnoses, only the 1-month MINI-Plus was used.

\section{Statistical Analyses}

The discriminant function of the WSQ was assessed for each of the MINI-Plus Axis 1 DSM-IV-TR disorders for which it screens, using sensitivity, specificity, receiver operating characteristics (ROC) curve (area under the curve [AUC]) [15], and positive and negative predictive values (PPVs, NPVs). Specificity was calculated as the proportion of patients who did not have the MINI-plus diagnosis and who had a negative WSQ screen. Sensitivity was determined as the proportion of patients with a MINI-Plus psychiatric diagnosis who had a positive WSQ screen for the same disorder. The AUC, (interpreted as the probability that a randomly selected clinical case will score higher on the test than a noncase), is not sensitive to prevalence and is proposed to correct this problem [16]; it can range from 0.50 (worthless test) to 1.00 (perfect test). Following Agresti (2002) [17], we considered the AUC to be of excellent evidence of concordance if $\geq 0.90$, good evidence of concordance if between 0.80 and 0.90 , acceptable although only average if between 0.70 and 0.80 , and poor if $<0.70$. The PPV was calculated as the percentage of participants with a positive test on the WSQ who actually had the disorder according to the
MINI-Plus diagnosis, whereas the NPV was calculated as the percentage of participants with a negative test that did not have the disorder according to the MINI-Plus. As the PPV and the NPV strongly depend on the prevalence of the disorder, we calculated these indices on the general population sample only, without the enrichment; otherwise, the results would be artificially inflated. Furthermore, WSQ cut-off scores were applied as originally recommended by Donker et al 2006 [8] and slightly adapted to fit within routine outcome monitoring (ROM), a monitoring system for psychiatric patient care [18]. All analyses were conducted using IBM SPSS version 20.0 for Windows.

\section{Results}

\section{Demographics and Prevalence of Diagnostic and Statistical Manual, 4th Edition-Text Revision (DSM-IV-TR) Diagnoses}

Characteristics of the two subsamples are presented in Table 1. In the total study group, the mean age was 39.6 years (range 18-65, standard deviation [SD]=12.6), and 60.53\% (782/1292) of the participants were female. Most participants were of Dutch origin $(1223 / 1292 ; 94.66 \%)$ and had completed a higher level of education $(972 / 1292 ; 75.23 \%)$. At baseline, $77.32 \%$ of the participants (999/1292) were employed, and 66.18\% (855/1292) were married. In the total group, 79 participants $(6.11 \%)$ met the DSM-IV-TR MINI-Plus criteria for a current (ie, within the past month) depressive (with or without anxiety) disorder. Of the total group, 139 participants $(10.76 \%)$ met the criteria for an anxiety with or without a depressive disorder; these participants were diagnosed according to the common subtypes of anxiety as indicated in Table 2 . In addition, 55 participants (4.26\%) met the criteria for current alcohol abuse or dependence disorder. The majority of the study group (934/1292, 72.29\%) did not pass the threshold for a current MINI-Plus diagnosis. It is recognized that the two study groups are not the same. The study population contains selected subgroups of particular interest; the difference in clinical and demographic characteristics within these subgroups contributes to define the target population. 
Table 1. Baseline sociodemographic and clinical characteristics of the two subsamples and the total study group ( $\mathrm{n}=1292$ ). The MINI International Neuropsychiatric Interview-Plus (MINI-Plus) 5.0.0 was used to collect diagnostic information. Participants can have more than one diagnosis.

\begin{tabular}{|c|c|c|c|}
\hline Characteristics & $\begin{array}{l}\text { General population sample } \\
(\mathrm{n}=1117)\end{array}$ & $\begin{array}{l}\text { Outpatient sample } \\
(\mathrm{n}=175)\end{array}$ & $\begin{array}{l}\text { Total study sample } \\
(\mathrm{n}=1292)\end{array}$ \\
\hline \multicolumn{4}{|l|}{ Baseline sociodemographic ${ }^{\mathrm{a}}$ characteristics } \\
\hline Age (years), mean $\left(\mathrm{SD}^{\mathrm{b}}\right)$ & $40.04(12.53)$ & $36.67(12.40)$ & $39.6(12.56)$ \\
\hline \multicolumn{4}{|l|}{ Gender, $\mathbf{n}(\%)$} \\
\hline Female & $712(63.74)$ & $70(40.0)$ & $782(60.53)$ \\
\hline \multicolumn{4}{|l|}{ Ethnical background $^{\mathrm{c}}, \mathbf{n}(\%)$} \\
\hline Dutch & $1116(99.91)$ & $160(91.4)$ & $1223(94.66)$ \\
\hline Other & $53(4.74)$ & $10(5.7)$ & $63(4.88)$ \\
\hline \multicolumn{4}{|l|}{ Educational status $^{\mathrm{d}}, \mathbf{n}(\%)$} \\
\hline Lower education & $250(22.38)$ & $64(36.6)$ & $314(24.30)$ \\
\hline Higher education & $866(77.53)$ & $106(60.6)$ & $972(75.23)$ \\
\hline \multicolumn{4}{|l|}{ Employment status, $n$ (\%) } \\
\hline Employed & $914(81.83)$ & $85(48.6)$ & $999(77.32)$ \\
\hline Unemployed or retired & $202(18.08)$ & $85(48.6)$ & $287(22.21)$ \\
\hline \multicolumn{4}{|l|}{ Marital status, n (\%) } \\
\hline Married or cohabitating & $766(68.58)$ & $89(50.9)$ & $855(66.18)$ \\
\hline \multicolumn{4}{|c|}{ Clinical characteristics or MINI ${ }^{\mathrm{e}}$-Plus Diagnosis ${ }^{\mathbf{f}}, \mathbf{n}(\%)$} \\
\hline Depressive (with or without anxiety) disorder & $12(1.07)$ & $67(38.3)$ & $79(6.11)$ \\
\hline Anxiety (with or without depressive) disorder & $60(5.37)$ & $79(45.1)$ & 139 (10.76) \\
\hline Panic disorder (without agoraphobia) & $4(0.36)$ & $24(13.7)$ & $28(2.17)$ \\
\hline Agoraphobia & $27(2.42)$ & $37(21.1)$ & $64(4.95)$ \\
\hline Panic disorder with agoraphobia & $2(0.18)$ & $18(10.3)$ & $20(1.55$ \\
\hline Social phobia & $10(0.09)$ & $9(5.1)$ & $19(1.47)$ \\
\hline Specific phobia & $9(0.81)$ & $3(1.7)$ & $12(0.93)$ \\
\hline Generalized anxiety disorder & $13(1.16)$ & $22(12.6)$ & $35(2.71)$ \\
\hline Posttraumatic stress disorder & $5(0.45)$ & $14(8.0)$ & 19 (1.47) \\
\hline Obsessive compulsive disorder & $6(0.54)$ & $3(1.7)$ & $9(0.70)$ \\
\hline Alcohol abuse or dependence & $51(4.57)$ & $4(2.3)$ & $55(4.26)$ \\
\hline No current DSM-IV-TR ${ }^{\mathrm{g}}$ diagnosis $^{\mathrm{h}}$ & $902(80.75)$ & $32(18.3)$ & $934(72.29)$ \\
\hline
\end{tabular}

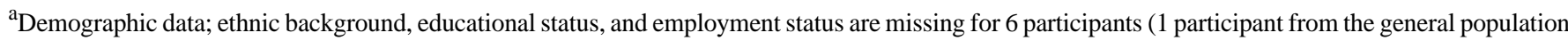
sample, and 5 outpatients).

${ }^{\mathrm{b}} \mathrm{SD}$ : standard deviation.

${ }^{\mathrm{c}}$ Dutch ethnic background was assumed when the participant was born in the Netherlands.

${ }^{\mathrm{d}}$ Lower education=having completed elementary school, lower general primary education, or no education at all; higher education=more than lower education (includes university).

${ }^{\mathrm{e}}$ MINI: Mini-International Neuropsychiatric Interview.

${ }^{\mathrm{f}}$ Clinical characteristics or diagnosis were missing for 1 participant.

g DSM-IV-TR: Diagnostic and Statistical Manual of Mental Disorders, 4th edition-Text Revision.

${ }^{\mathrm{h}}$ Denotes participants who did not pass the threshold for having a current Axis- I DSM-IV-TR diagnosis according to the MINI-Plus interview.
} 
Table 2. Agreement between the Mini-International Neuropsychiatric Interview (MINI)-Plus and the Web Screening Questionnaire (WSQ) for individual disorders in the total sample $(\mathrm{n}=1292)$. Numbers in the table reflect the use of each screening subscale to detect any diagnosis rather than only the diagnosis associated with the subscale. WSQ cut-off scores were derived from the original cut-offs recommended by Donker et al (2009) [8]. WSQ cut-off scores: depression: Q1 $\geq 5$ and Q2=1; panic disorder: Q4 $\geq 1$; agoraphobia Q5=1; panic disorder with agoraphobia Q4 $\geq 1$ and Q5=1; social phobia: Q8=1 and Q9=1; specific phobia: Q6 or Q7=1; generalized anxiety disorder (GAD): Q3 $\geq 2$; post-traumatic stress disorder (PTSD): Q10=1 or Q11=1; obsessive compulsive disorder (OCD): Q12 $\geq 1$; and alcohol abuse or dependence: Q13 $\geq 2$ and Q14 $\geq 3$.

\begin{tabular}{|c|c|c|c|c|c|c|c|c|c|}
\hline $\begin{array}{l}\text { DSM-IV-TR } \\
\text { diagnosis }\end{array}$ & $\begin{array}{l}\mathrm{MINI}^{\mathrm{b}} \\
\text { prevalence } \\
(\%)\end{array}$ & $\begin{array}{l}\mathrm{WSQ}^{\mathrm{c}} \\
\text { prevalence } \\
(\%)\end{array}$ & $\begin{array}{l}\text { True } \\
\text { positive }\end{array}$ & $\begin{array}{l}\text { False } \\
\text { positive }\end{array}$ & $\begin{array}{l}\text { False } \\
\text { negative }\end{array}$ & $\begin{array}{l}\text { True } \\
\text { negative }\end{array}$ & $\begin{array}{l}\text { Specificity } \\
(95 \% \text { CI })\end{array}$ & $\begin{array}{l}\text { Sensitivity } \\
(95 \% \mathrm{CI})\end{array}$ & $\begin{array}{l}\text { AUC }^{\mathrm{d}} \\
(95 \% \mathrm{CI})\end{array}$ \\
\hline Depressive disorder & $79(6.11)$ & $115(8.90)$ & 46 & 69 & 33 & 1144 & $\begin{array}{l}0.94(0.93- \\
0.96)\end{array}$ & $\begin{array}{l}0.58(0.47- \\
0.69)\end{array}$ & $\begin{array}{l}0.83(0.68- \\
0.98)\end{array}$ \\
\hline Panic disorder & $28(2.16)$ & $170(13.16)$ & 28 & 142 & 0 & 1122 & $\begin{array}{l}0.89(0.87- \\
0.90)\end{array}$ & $\begin{array}{l}1.00(0.88- \\
1.00)\end{array}$ & $\begin{array}{l}0.98(0.96- \\
1.00)\end{array}$ \\
\hline Agoraphobia & $64(4.95)$ & $111(8.59)$ & 52 & 59 & 12 & 1169 & $\begin{array}{l}0.95(0.94- \\
0.96)\end{array}$ & $\begin{array}{l}0.81(0.70- \\
0.90)\end{array}$ & $\begin{array}{l}0.80(0.69- \\
0.91)\end{array}$ \\
\hline $\begin{array}{l}\text { Panic disorder with } \\
\text { agoraphobia }\end{array}$ & $20(1.55)$ & $61(4.72)$ & 18 & 43 & 2 & 1229 & $\begin{array}{l}0.97(0.96- \\
0.98)\end{array}$ & $\begin{array}{l}0.90(0.68- \\
0.99)\end{array}$ & $\begin{array}{l}0.99(0.98- \\
1.00)\end{array}$ \\
\hline Social phobia & $19(1.47)$ & $101(7.82)$ & 15 & 86 & 4 & 1187 & $\begin{array}{l}0.93(0.92- \\
0.95)\end{array}$ & $\begin{array}{l}0.79(0.54- \\
0.94)\end{array}$ & $\begin{array}{l}0.95(0.92- \\
0.99)\end{array}$ \\
\hline Specific phobia & $12(0.93)$ & $363(28.10)$ & 12 & 351 & 0 & 929 & $\begin{array}{l}0.73(0.70- \\
0.75)\end{array}$ & $\begin{array}{l}1.00(0.74- \\
1.00)\end{array}$ & $\begin{array}{l}0.93(0.89- \\
0.97)\end{array}$ \\
\hline $\begin{array}{l}\text { Generalized anxiety } \\
\text { disorder }\end{array}$ & $35(2.71)$ & $145(11.22)$ & 23 & 122 & 12 & 1135 & $\begin{array}{l}0.90(0.89- \\
0.92)\end{array}$ & $\begin{array}{l}0.66(0.48- \\
0.81)\end{array}$ & $\begin{array}{l}0.89(0.79- \\
0.99)\end{array}$ \\
\hline $\begin{array}{l}\text { Post-traumatic stress } \\
\text { disorder }\end{array}$ & $19(1.47)$ & $621(48.07)$ & 15 & 606 & 4 & 667 & $\begin{array}{l}0.52(0.50- \\
0.55)\end{array}$ & $\begin{array}{l}0.79(0.54- \\
0.94)\end{array}$ & $\begin{array}{l}0.86(0.74- \\
0.98)\end{array}$ \\
\hline $\begin{array}{l}\text { Obsessive compulsive } \\
\text { disorder }\end{array}$ & $9(0.69)$ & $120(9.3)$ & 6 & 114 & 3 & 1169 & $\begin{array}{l}0.91(0.89- \\
0.92)\end{array}$ & $\begin{array}{l}0.67(0.30- \\
0.93)\end{array}$ & $\begin{array}{l}0.82(0.59- \\
1.00)\end{array}$ \\
\hline $\begin{array}{l}\text { Alcohol abuse or de- } \\
\text { pendence }\end{array}$ & $55(4.26)$ & $121(9.37)$ & 31 & 90 & 24 & 1147 & $\begin{array}{l}0.93(0.91- \\
0.94)\end{array}$ & $\begin{array}{l}0.56(0.42- \\
0.70)\end{array}$ & $\begin{array}{l}0.82(0.75- \\
0.88)\end{array}$ \\
\hline
\end{tabular}

${ }^{a}$ DSM- IV-TR: Diagnostic and Statistical Manual of Mental Disorders, 4th edition-Text Revision.

${ }^{b}$ MINI: Mini International Neuropsychiatric Interview; MINI-Plus 5.0.0.

${ }^{c}$ WSQ: Web Screening Questionnaire.

${ }^{\mathrm{d}}$ AUC: area under the curve.

\section{Concordance Between Mini-International Neuropsychiatry Interview (MINI)-Plus and Web Screening Questionnaire (WSQ)}

The concordance between each diagnosis classified according to the DSM-IV-TR with the MINI-Plus and the WSQ questionnaire is presented in Table 2. Specificity was high (range 0.89-0.97) for most individual disorders, with the exception of specific phobia (0.73) and PTSD (0.52). Sensitivity was substantial to high (0.67 to 1.00$)$ for the majority of disorders. The exceptions were depressive disorder $(0.58)$ and alcohol abuse or dependence (0.56). All AUC values were good to excellent $(\geq 0.82)$ for the individual disorders. The best discriminating subscale was panic disorder with agoraphobia (AUC $=0.99$ ), followed by panic disorder $(\mathrm{AUC}=0.98)$ and social phobia (AUC=0.95). Figure 1 presents the discriminative power of each subscale of the WSQ. Data on PPCs and NPVs are given in Table 3. These indices were calculated for the general population subsample only because of the strong relation to the prevalence of the disorders. Despite generally strong discriminative power, the PPV was of poor strength ranging from 0.01 (PTSD) to 0.33 (agoraphobia); the NPVs were uniformly high $(\geq 0.97)$ for all scales. 
Figure 1. Distribution of the MINI-Plus diagnosis for the corresponding Web Screening Questionaire (WSQ) subscales in the study sample (N=1292) MINI-Plus=The MINI International Neuropsychiatric Interview-Plus 5.0.0. WSQ=Web Screening Questionnaire. WSQ cut-off scores were derived from the original cut-offs recommended by Donker and colleagues (2009) [8]. WSQ cut-off scores: depression: Q1 $\geq 5$ and Q2=1; panic disorder: Q4 $\geq 1$; agoraphobia: Q5=1; panic disorder with agoraphobia Q4 $\geq 1$ and Q5=1; social phobia: Q8=1 and Q9=1; specific phobia: Q6 or Q7=1; generalized anxiety disorder (GAD): Q3 22; post-traumatic stress disorder (PTSD): Q10=1 or Q11=1; obsessive compulsive disorder (OCD): Q12 $\geq 1$; and alcohol abuse or dependence : Q13 $\geq 2 \&$ Q14 $\geq 3$. MINI-Plus: The Mini-International Neuropsychiatric Interview-Plus 5.0.0. WSQ: Web Screening Questionnaire.

MINI diagnosis absent

MINI diagnosis present

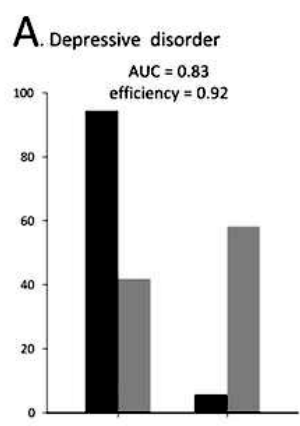

WSQ score: $\quad 0-1$

F. Specific phobia

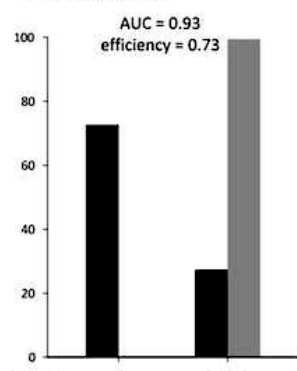

WSQ score:

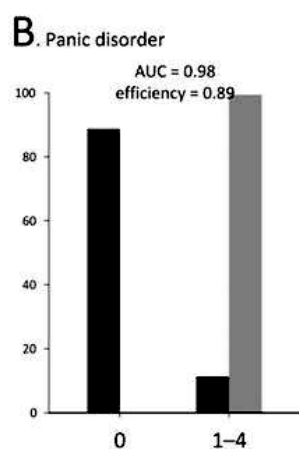

G. Generalized anxiety disorder

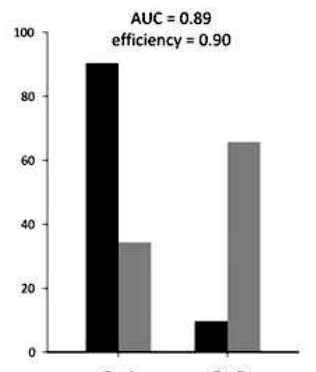

$0-1$
C. Agoraphobia

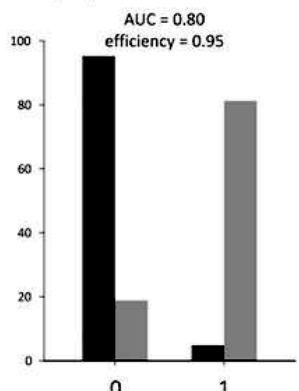

0

H. Posttraumatic stress disorder

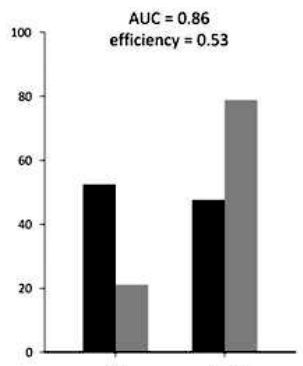

0

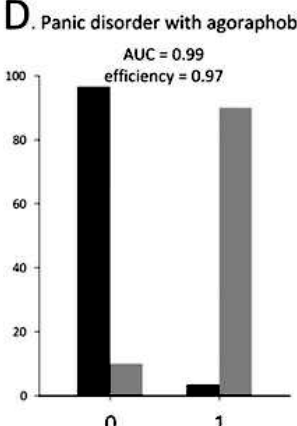

0
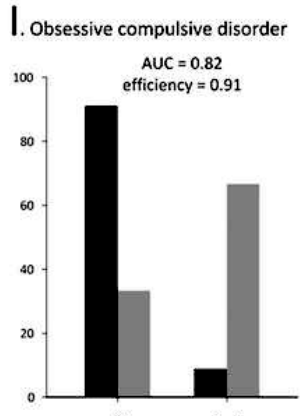

$0 \quad 1-4$
E. Social phobia

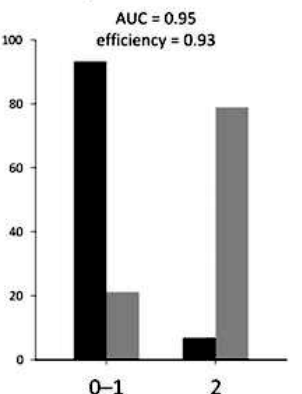

$0-1$

J. Alcohol abuse/dependence

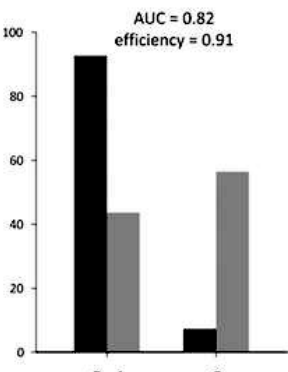


Table 3. Predictive value of the Web Screening Questionnaire (WSQ) for individual disorders according to the Mini-International Neuropsychiatry Interview (MINI)-Plus in the general population subsample $(\mathrm{n}=1117)$. Numbers in the table reflect the use of each screening subscale to detect any diagnosis rather than only the diagnosis associated with the subscale. WSQ cut-off scores were derived from the original cut-offs recommended by Donker et al (2009) [8]. WSQ cut-off scores: depression: Q1 $\geq 5$ and Q2=1; panic disorder: Q4 $\geq 1$; agoraphobia: Q5=1; panic disorder with agoraphobia $\mathrm{Q} 4 \geq 1$ and Q5=1; social phobia: Q8=1 and Q9=1; specific phobia: Q6 or Q7=1; generalized anxiety disorder (GAD): Q3 $\geq 2$; post-traumatic stress disorder (PTSD): Q10=1 or Q11=1; obsessive compulsive disorder (OCD): Q12 $\geq 1$; and alcohol abuse or dependence: Q13 2 and Q14 $\geq 3$.

\begin{tabular}{|c|c|c|c|c|c|c|c|c|}
\hline $\begin{array}{l}\text { DSM-IV-TR } \\
\text { diagnosis }\end{array}$ & $\begin{array}{l}\mathrm{MINI}^{\mathrm{b}} \\
\text { prevalence } \\
(\%)\end{array}$ & $\begin{array}{l}\mathrm{WSQ}^{\mathrm{c}} \\
\text { prevalence } \\
(\%)\end{array}$ & $\begin{array}{l}\text { True } \\
\text { positive }\end{array}$ & $\begin{array}{l}\text { False } \\
\text { positive }\end{array}$ & $\begin{array}{l}\text { False } \\
\text { negative }\end{array}$ & $\begin{array}{l}\text { True } \\
\text { negative }\end{array}$ & $\begin{array}{l}\text { PPV }^{\mathrm{d}} \\
(95 \% \mathrm{CI})\end{array}$ & $\begin{array}{l}\mathrm{NPV}^{\mathrm{e}} \\
(95 \% \mathrm{CI})\end{array}$ \\
\hline Depressive disorder & $12(1.107$ & $28(2.51)$ & 6 & 22 & 6 & 1083 & $\begin{array}{l}0.21(0.08- \\
0.41)\end{array}$ & $\begin{array}{l}0.99(0.99- \\
1.00)\end{array}$ \\
\hline Panic disorder & $4(0.36)$ & $64(5.73)$ & 4 & 60 & 0 & 1053 & $\begin{array}{l}0.06(0.02- \\
0.15)\end{array}$ & $\begin{array}{l}1.00(0.99- \\
1.00)\end{array}$ \\
\hline Agoraphobia & $27(2.42)$ & $52(4.66)$ & 17 & 35 & 10 & 1055 & $\begin{array}{l}0.33(0.20- \\
0.47)\end{array}$ & $\begin{array}{l}0.99(0.98- \\
1.00)\end{array}$ \\
\hline Panic disorder with agoraphobia & $2(0.18)$ & $11(0.98)$ & 2 & 9 & 0 & 1106 & $\begin{array}{l}0.18(0.02- \\
0.52)\end{array}$ & $\begin{array}{l}1.00(0.99- \\
1.00)\end{array}$ \\
\hline Social phobia & $9(0.81)$ & $47(4.21)$ & 7 & 40 & 3 & 1067 & $\begin{array}{l}0.15(0.06- \\
0.28)\end{array}$ & $\begin{array}{l}1.00(0.99- \\
1.00)\end{array}$ \\
\hline Specific phobia & $9(0.81)$ & $281(25.16)$ & 9 & 272 & 0 & 836 & $\begin{array}{l}0.03(0.01- \\
0.06)\end{array}$ & $\begin{array}{l}1.00(0.99- \\
1.00)\end{array}$ \\
\hline Generalized anxiety disorder & $13(1.16)$ & $46(4.12)$ & 8 & 38 & 5 & 1066 & $\begin{array}{l}0.17(0.08- \\
0.31)\end{array}$ & $\begin{array}{l}1.00(0.99- \\
1.00)\end{array}$ \\
\hline Post-traumatic stress disorder & $5(0.45)$ & $511(45.75)$ & 5 & 506 & 0 & 606 & $\begin{array}{l}0.01(0.03- \\
0.02)\end{array}$ & $\begin{array}{l}1.00(0.99- \\
1.00)\end{array}$ \\
\hline Obsessive compulsive disorder & $6(0.54)$ & $55(4.92)$ & 4 & 51 & 2 & 1060 & $\begin{array}{l}0.07(0.02- \\
0.18)\end{array}$ & $\begin{array}{l}1.00(0.99- \\
1.00)\end{array}$ \\
\hline Alcohol abuse or dependence & $51(4.57)$ & $110(9.85)$ & 28 & 82 & 23 & 984 & $\begin{array}{l}0.25(0.18- \\
0.35)\end{array}$ & $\begin{array}{l}0.98(0.97- \\
0.99)\end{array}$ \\
\hline
\end{tabular}

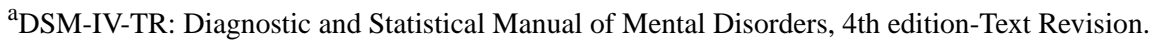

${ }^{b}$ MINI: Mini International Neuropsychiatric Interview; MINI-Plus 5.0.0.

${ }^{\mathrm{c}}$ WSQ: Web Screening Questionnaire.

${ }^{\mathrm{d}} \mathrm{PPV}$ : positive predictive value.

${ }^{\mathrm{e}} \mathrm{NPV}$ : negative predictive value.

\section{Discussion}

\section{Principal Findings}

This study evaluated the feasibility of the WSQ to screen for DSM-IV-TR diagnoses of depressive disorder, anxiety disorders, and alcohol abuse or dependence. Overall, the WSQ was relatively successful in discriminating between individuals with and without a MINI-Plus diagnosis. However, if the WSQ tests positive for a psychiatric disorder, further examination is warranted because of the poor PPVs. Thus, most patients who tested positively, did not receive a MINI-Plus diagnosis.

The adequate strength of the findings regarding sensitivity, specificity, and AUC values suggest that the WSQ has some desirable screening characteristics. Its high sensitivity suggests that it may help to confirm the absence of most of these psychiatric diagnoses, that is, ruling out the disorders. However, the exceptions are depressive disorder, specific phobia, PTSD, and alcohol abuse or dependence, for which the agreement in ruling out these psychiatric disorders was lower. In the general population subsample, the NPVs were high, but the PPVs were relatively low compared with the MINI-Plus results. Although the PPVs and NPVs are not intrinsic to the test, they are directly related to the prevalence of the disease in the population. Assuming all other factors remain constant, PPV increases with increasing prevalence, and NPV decreases with an increase in prevalence.

Together with the results reported by Donker and colleagues [8] who found AUCs of 0.65 to 0.83 in their validation of the WSQ against DSM-IV-TR diagnoses with the CIDI in the general population, the present results indicate that the WSQ has potential as a screener, ruling out the presence of a disorder.

Our findings are in line with other validation studies comparing brief screening tools with longer ones and also showing the feasibility of these short screening instruments. This applies, for example, to the Psychiatric Diagnostic Screening Questionnaire (PDSQ) in outpatients $[19,20]$ and the Mental Health Inventory 5 (MHI-5) and the Anxiety and Depression Detector (ADD) for primary care populations [21-23]. 


\section{Strengths and Limitations}

A strength of this study is the large number of participants included. Another strength is that our MINI-Plus data allowed to determine the concordance of the WSQ with the last 1-month DSM-IV-TR diagnoses, providing an accurate measure of the current (or very recent) prevalence of this mental disorder. In contrast, Donker and colleagues (2009) [8] used 6-month prevalence rates, which implies that some disorders could have receded during the past 5 months.

A limitation of this study is that all the GP practices included were affiliated with a university hospital. Because such practices tend to have more focus on research and training than nonaffiliated practices, this may have introduced bias in the study group population. Moreover, the study group was mainly compiled from participants included in an earlier general population study [12]; these participants did not have psychiatric treatment for 6 months before recruitment and did not report dependence on alcohol or other drugs. Although we made considerable effort to compensate for this potential source of bias in recruitment by adding a psychiatric outpatient subsample [13], the prevalence of psychiatric disorders in our general population subsample was substantially lower than expected from population-based surveys in the Netherlands [24,25]. Therefore, it is likely that we probably included an overly healthy study group, thereby limiting the generalizability of these results to the general population or other patient samples. Therefore, the present results need to be confirmed in other study populations. As a result, the NPV estimates may have been too high and the PPV too low. Our findings with regard to the predictive value must be considered extreme, given the very low prevalence of disorders in the present sample. In addition, as the number of participants with certain conditions was small, this yielded less precise effect estimates, which should be taken into account when interpreting these results. Predictive values from one study should not be transferred to another setting with a different prevalence of the disease in the population. However, our estimates of the sensitivity, specificity, and AUC are not affected by this limitation. Moreover, reconsidering the diagnostic criteria and the screening items used for the individual WSQ items could contribute to a higher accuracy of detecting disorders and higher positive and predictive values.

A final limitation is that our sample was restricted to Dutch-speaking individuals able to write (illiterate or non-Dutch speaking persons were excluded); this may also limit the generalizability of our results, especially across different immigrant groups. In addition, future research could investigate the impact of demographic factors on our study results. Although it is generally assumed that structured diagnostic interviews (ie, the MINI-Plus and SCID) are the "gold standards" for the assessment of diagnoses in psychiatric research, these standards have their limitations. One advantage for reproducibility is that it is fully clear what standardized procedures had been followed. However, the notion that mental disorders (eg, depression and anxiety) are entities that can be diagnosed remains debatable, despite the apparent clinical value of such diagnoses.

\section{Conclusions}

The WSQ is a short questionnaire to screen for depression, GAD, panic disorder with or without agoraphobia, social phobia, specific phobia, OCD, PTSD, and alcohol abuse or dependence. In has proven useful in the general population to screen for the 6-months prevalence for these disorders, compared with the CIDI as gold standard [8]. This study yielded similar results, with the 1-month prevalence of these disorders in the MINI-Plus in a general practice population, combined with psychiatric outpatients. Taken together, exploring the agreement between both instruments, or findings, indicates that the WSQ can (potentially) be used as a brief and less costly screening tool for depressive or anxiety disorders (except for PTSD and specific phobia). The WSQ seems a promising tool with a two-step diagnostic approach, for example, in primary care. It could assist health care providers in screening patients before consultation. Patients who screen positive should undergo more extensive diagnostic procedures, whereas a negative screen indicates that it is highly unlikely that further evaluation would be useful. With such an approach, diagnostic accuracy might be increased and costly diagnostic procedures limited or avoided.

However, this study had several limitations which should be considered when interpreting and generalizing our finding to other groups. For example, participant recruitment was not standard, and recruitment barriers could not be completely eliminated. Also, in our study group, the prevalence of psychiatric disorders was lower than expected. Moreover, concern still exists about the usefulness of the WSQ in its current form; some revision of the scale may be required to improve its psychometric properties. Future research exploring the feasibility of the WSQ for assessing mental health in general practice might be a further step in the economization and optimization of mental health care.

\section{Acknowledgments}

This is a collaborative study between Rivierduinen (RD) and the department of Psychiatry of the Leiden University Medical Center (LUMC) and is funded entirely by RD.

\section{Conflicts of Interest}

None declared.

\section{Multimedia Appendix 1}

Web Screening Questionnaire (WSQ). 


\section{References}

1. Kessler RC, Andrews G, Mroczek D, Ustun B, Wittchen H. The World Health Organization Composite International Diagnostic Interview short-form (CIDI-SF). Int J Method Psychiat Res 1998 Nov;7(4):171-185. [doi: 10.1002/mpr.47]

2. Spitzer RL, Williams JB, Gibbon M, First MB. The structured clinical interview for DSM-III-R (SCID). I: history, rationale, and description. Arch Gen Psychiatry 1992 Aug;49(8):624-629. [Medline: 1637252]

3. Ramirez Basco M, Bostic JQ, Davies D, Rush AJ, Witte B, Hendrickse W, et al. Methods to improve diagnostic accuracy in a community mental health setting. Am J Psychiatry 2000 Oct;157(10):1599-1605. [doi: 10.1176/appi.ajp.157.10.1599] [Medline: 11007713]

4. Robins LN, Wing J, Wittchen HU, Helzer JE, Babor TF, Burke J, et al. The Composite International Diagnostic Interview. An epidemiologic instrument suitable for use in conjunction with different diagnostic systems and in different cultures. Arch Gen Psychiatry 1988 Dec;45(12):1069-1077. [Medline: 2848472]

5. Kessler RC, Ustün TB. The World Mental Health (WMH) Survey Initiative Version of the World Health Organization (WHO) Composite International Diagnostic Interview (CIDI). Int J Methods Psychiatr Res 2004;13(2):93-121. [Medline: 15297906]

6. Sheehan DV, Lecrubier Y, Sheehan KH, Amorim P, Janavs J, Weiller E, et al. The Mini-International Neuropsychiatric Interview (M.I.N.I.): the development and validation of a structured diagnostic psychiatric interview for DSM-IV and ICD-10. J Clin Psychiatry 1998;59(Suppl 20):22-33. [Medline: 9881538]

7. Lecrubier Y, Sheehan D, Weiller E, Amorim P, Bonora I, Harnett Sheehan K, et al. The Mini International Neuropsychiatric Interview (MINI). A short diagnostic structured interview: reliability and validity according to the CIDI. Eur Psychiatry 1997;12(5):224-231 [FREE Full text] [doi: 10.1016/S0924-9338(97)83296-8]

8. Donker T, van Straten A, Marks I, Cuijpers P. A brief Web-based screening questionnaire for common mental disorders: development and validation. J Med Internet Res 2009 Jul 24;11(3):e19 [FREE Full text] [doi: 10.2196/jmir.1134] [Medline: 19632977]

9. Diagnostic and Statistical Manual of Mental Disorders, 4th Edition. Washington, D.C: American Psychiatric Association; 2000.

10. Boerma WG, van der Zee J, Fleming DM. Service profiles of general practitioners in Europe. European GP Task Profile Study. Br J Gen Pract 1997 Aug;47(421):481-486 [FREE Full text] [Medline: 9302786]

11. Schäfer W, Kroneman M, Boerma W, van den Berg M, Westert G, Devillé W, et al. The Netherlands: health system review. Health Syst Transit 2010;12(1):v-xxvii, 1-228 [FREE Full text] [Medline: 21132996]

12. Schulte-van Maaren YW, Carlier IV, Giltay EJ, van Noorden MS, de Waal MW, van der Wee NJ, et al. Reference values for mental health assessment instruments: objectives and methods of the Leiden Routine Outcome Monitoring Study. J Eval Clin Pract 2013 Apr;19(2):342-350. [doi: 10.1111/j.1365-2753.2012.01830.x] [Medline: 22332898]

13. Meuldijk D, Carlier IV, van Vliet IM, van den Akker- Marle ME, Zitman FG. A randomized controlled trial of the efficacy and cost-effectiveness of a brief intensified cognitive behavioral therapy and/or pharmacotherapy for mood and anxiety disorders: design and methods. Contemp Clin Trials 2012 Sep;33(5):983-992. [doi: 10.1016/j.cct.2012.05.002] [Medline: 22588010]

14. Gega L, Kenwright M, Mataix-Cols D, Cameron R, Marks IM. Screening people with anxiety/depression for suitability for guided self-help. Cogn Behav Ther 2005;34(1):16-21. [doi: 10.1080/16506070410015031] [Medline: 15844684]

15. Hanley JA, Lippman-Hand A. If nothing goes wrong, is everything all right? Interpreting zero numerators. JAMA 1983 Apr 1;249(13):1743-1745. [doi: 10.1001/jama.1983.03330370053031] [Medline: $\underline{6827763]}$

16. Cohen J. A coefficient of agreement for nominal scales. Educ Psychol Meas 1960 Apr 1;20(1):37-46 [FREE Full text] [doi: 10.1177/001316446002000104]

17. Agresti A. Categorical data analysis. New York: John Wiley \& Sons; 2003.

18. de Beurs E, den Hollander-Gijsman ME, van Rood YR, van der Wee NJ, Giltay EJ, van Noorden MS, et al. Routine outcome monitoring in the Netherlands: practical experiences with a web-based strategy for the assessment of treatment outcome in clinical practice. Clin Psychol Psychother 2011;18(1):1-12. [doi: 10.1002/cpp.696] [Medline: 20238371]

19. Zimmerman M, Mattia JI. A self-report scale to help make psychiatric diagnoses: the Psychiatric Diagnostic Screening Questionnaire. Arch Gen Psychiatry 2001 Aug;58(8):787-794. [doi: 10.1001/archpsyc.58.8.787] [Medline: 11483146]

20. Zimmerman M, Mattia JI. The Psychiatric Diagnostic Screening Questionnaire: development, reliability and validity. Compr Psychiatry 2001;42(3):175-189. [doi: 10.1053/comp.2001.23126] [Medline: 11349235]

21. Cuijpers P, Smits N, Donker T, ten Have M, de Graaf R. Screening for mood and anxiety disorders with the five-item, the three-item, and the two-item Mental Health Inventory. Psychiatry Res 2009 Aug 15;168(3):250-255. [doi:

10.1016/j.psychres.2008.05.012] [Medline: 19185354]

22. Rumpf HJ, Meyer C, Hapke U, John U. Screening for mental health: validity of the MHI-5 using DSM-IV Axis I psychiatric disorders as gold standard. Psychiatry Res 2001 Dec 31;105(3):243-253. [doi: 10.1016/S0165-1781(01)00329-8] [Medline: 11814543] 
23. Means-Christensen AJ, Sherbourne CD, Roy-Byrne PP, Craske MG, Stein MB. Using five questions to screen for five common mental disorders in primary care: diagnostic accuracy of the Anxiety and Depression Detector. Gen Hosp Psychiatry 2006;28(2):108-118. [doi: 10.1016/j.genhosppsych.2005.08.010] [Medline: 16516060 ]

24. de Graaf R, ten Have M, van Gool C, van Dorsselaer S. Prevalence of mental disorders and trends from 1996 to 2009. Results from the Netherlands Mental Health Survey and Incidence Study-2. Soc Psychiatry Psychiatr Epidemiol 2012 Feb;47(2):203-213. [doi: 10.1007/s00127-010-0334-8] [Medline: 21197531]

25. Bijl RV, Ravelli A, van Zessen G. Prevalence of psychiatric disorder in the general population: results of The Netherlands Mental Health Survey and Incidence Study (NEMESIS). Soc Psychiatry Psychiatr Epidemiol 1998 Dec;33(12):587-595. [Medline: 9857791$]$

\author{
Abbreviations \\ ADD: anxiety and depression detector \\ AUC: area under the curve \\ CIDI: Composite International Diagnostic Interview \\ DSM-IV-TR: Diagnostic and Statistical Manual of Mental Disorders, 4th edition-Text Revision \\ GP: general practitioner \\ ICD-10: The International Classification of Diseases and Related Health Problems \\ GAD: generalized anxiety disorder \\ LUMC: Leiden University Medical Center \\ MEC: Medical Ethical Committee \\ MHI-5: Mental Health Inventory-5 \\ MHC: mental health clinics \\ MINI-Plus: Mini-International Neuropsychiatric Interview-Plus \\ NPV: negative predictive values \\ OCD: obsessive compulsive disorder \\ PPV: positive predictive values \\ PDSQ: Psychiatric Diagnostic Screening Questionnaire \\ PTSD: post-traumatic stress disorder \\ RCT: randomized controlled trial \\ RD: Rivierduinen \\ RHMP: regional mental health provider \\ ROC: receiver operating characteristic \\ ROM: routine outcome monitoring \\ WSQ: Web Screening Questionnaire
}

Edited by G Eysenbach; submitted 18.12.15; peer-reviewed by W van Ballegooijen, LMclellan, D Meyer; comments to author 03.04.16;
revised version received 30.11.16; accepted 06.06.17; published 29.08.17
Please cite as:
Meuldijk D, Giltay EJ, Carlier IVE, van Vliet IM, van Hemert AM, Zitman FG
A Validation Study of the Web Screening Questionnaire (WSQ) Compared With the Mini-International Neuropsychiatric Interview-Plus
(MINI-Plus)
JMIR Ment Health 2017;4(3):e35
URL: $\underline{\text { http://mental.jmir.org/2017/3/e35/ }}$
doi: $10.2196 /$ mental.5453
PMID: $\underline{28851674}$

CDenise Meuldijk, Erik J Giltay, Ingrid VE Carlier, Irene M van Vliet, Albert M van Hemert, Frans G Zitman. Originally published in JMIR Mental Health (http://mental.jmir.org), 29.08.2017. This is an open-access article distributed under the terms of the Creative Commons Attribution License (https://creativecommons.org/licenses/by/4.0/), which permits unrestricted use, distribution, and reproduction in any medium, provided the original work, first published in JMIR Mental Health, is properly cited. The complete bibliographic information, a link to the original publication on http://mental.jmir.org/, as well as this copyright and license information must be included. 